\title{
Mixed Convection MHD Flow of a Casson Nanofluid over a Nonlinear Permeable Stretching Sheet with Viscous Dissipation
}

\author{
Prabhakar Besthapu ${ }^{1}$, Shanker Bandari ${ }^{2}$ \\ ${ }^{1}$ Department of Mathematics, Govt. Degree \& P. G. College, Peddapalli, India \\ ${ }^{2}$ Department of Mathematics, Osmania University, Hyderabad, India \\ Email: prabhakarbesthapu@gmail.com, bandarishanker@yahoo.co.in
}

Received 1 October 2015; accepted 8 December 2015; published 11 December 2015

Copyright (C) 2015 by authors and Scientific Research Publishing Inc.

This work is licensed under the Creative Commons Attribution International License (CC BY). http://creativecommons.org/licenses/by/4.0/

(c) (i) Open Access

\section{Abstract}

The present study deals with the mixed convection MHD flow of a Casson nanofluid over a nonlinear permeable stretching sheet with viscous dissipation. The governing partial differential equations are transformed into nonlinear coupled ordinary differential equations with the help of suitable similarity transformations. These equations were then solved numerically by using an implicit finite difference method known as Keller-Box method. The effects of various parameters such as magnetic parameter $(M)$, Casson parameter $(\beta)$, local Grashoff number $(G r)$, local modified Grashoff number $(G c)$, nonlinear parameter $(n)$, Eckert number $(E c)$ on velocity, temperature and concentration were discussed and presented graphically. It is found that a larger value of Casson parameter leads to decrease the velocity and temperature. Increase in the local Grashoff number reduces the temperature. Nanoparticle concentration is decreased for the larger values of local Modified Grashoff number. The numerical values of skin friction, Nusselt number and Sherwood number are presented in tables.

\section{Keywords}

MHD, Nonlinear Permeable Stretching Sheet, Mixed Convection, Casson Fluid

\section{Introduction}

The study of boundary layer flows with the combined effects of heat and mass transfer over stretching or moving surfaces is quite essential due to its various applications in industrial and engineering processes, for example, in manufacture and extraction of polymer and rubber sheets. Sakiadis [1] [2] was the first to study the boundary 
layer flow over a continuously moving surface. The suitable similarity transformations were used to obtain numerical solution for the problem. Later this work was extended by Erickson et al. [3] in which the transverse velocity was non-zero, at the moving surface with heat and mass transfer in the boundary layer being taken into account.

Magyari and Keller [4] investigated the stretching problem of an incompressible fluid over a permeable wall. On the other hand, Gupta and Gupta [5], have mentioned that the stretching of the sheet may not necessarily be linear. In view of this, Vajravelu [6] studied the flow and heat transfer in a viscous fluid over a nonlinear stretching sheet. Bhargava et al. [7] examined the flow of a micro polar fluid over a nonlinear stretching sheet. Recently, Prasad et al. [8] studied the heat transfer analysis with the effect of mixed convection over a nonlinear stretching surface with variable fluid properties.

Nanofluid is a new type of heat transfer fluid which contains a base fluid and nanoparticles. The term nanofluid was proposed by Choi [9]. Nanofluids are used to increase the thermal conductivity of base fluids like water, ethylene glycol, propylene glycol, etc. They have various engineering and biomedical applications in cooling, cancer therapy and process industries. The pioneer work on the boundary layer flow of a nanofluid over a stretching sheet has been carried out by Khan and Pop [10] using Buongiorno's model [11]. The boundary layer flow of a nanofluid induced by a stretching surface has drawn the attention of many researchers [12]-[14]. Rana and Bhargava [15] investigated the boundary layer flow of a nanofluid flow over a nonlinearly stretching sheet. Recently Mabood et al. [16] numerically studied the MHD boundary layer flow and heat transfer of nanofluids over a nonlinear stretching sheet.

In real life applications many materials like shampoos, printing ink, muds, condensed milk, paints, and tomato paste, etc., show different characters which cannot be understood by Newtonian theory. So to describe such type of fluids it is necessary to introduce the non-Newtonian fluids. The fluid which does not obey Newton's law of viscosity is known as non Newtonian fluid. All the properties of non-Newtonian fluid cannot be expressed in a single non-Newtonian model; various models have been proposed in the literature and these models mainly categorized into three types namely differential, rate and integral type fluids.

In the year of 1959, a model presented in the flow of viscoelastic fluid by Casson which was known as a Casson fluid model. Casson fluid exhibits a yield stress. It is well known that Casson fluid is a shear thinning liquid which is assumed to have an infinite viscosity at zero rate of shear, a yield stress below which no flow occurs, and a zero viscosity at an infinite rate of shear, i.e., if a shear stress less than the yield stress is applied to the fluid it behaves like a solid, whereas if a shear stress greater than yield stress is applied it starts to move. Fredrickson [17] investigated the steady flow behavior of a Casson fluid in a tube. M. Nakamura et al. [18], studied the flow of a non-Newtonian fluid through an axisymmetric stenosis numerically. Mustafa et al. [19] studied and solved analytically using homotopy analysis method (HAM) for the problem unsteady boundary layer flow with heat transfer of a Casson fluid over a moving flat plate with a parallel free stream and the concept of MHD flow of the Casson fluid model over an exponentially shrinking sheet has been presented by Nadeem et al. [20]. An exact solution of the steady boundary layer flow of Casson fluid over a stretching or shrinking sheet was studied by Bhattacharyya et al. [21], and analytical solution has been given by Krishnendu Bhattacharyya et al. [22] for the problem MHD boundary layer flow of Casson fluid over stretching/shrinking sheet with wall mass transfer whereas Swati Mukhopadhyay [23] studied Casson fluid flow and heat transfer over a nonlinearly stretching surface. On the other hand Peri K. Kameswaran et al. [24] investigated and presented Dual solutions of Casson fluid flow over a stretching or shrinking sheet. Rizwan Ul Haq et al. [25] studied the flow of Casson nanofluid over an exponential shrinking sheet with convective heat transfer and MHD effects. Recently the MHD flow of a Casson nanofluid with viscous dissipation over an exponentially stretching sheet by considering convective conditions is studied by T. Hussain et al. [26]. M. Mustafa and Junaid Ahmad Khan [27], discussed a model for the flow of Casson nanofluid past a nonlinearly stretching sheet considering magnetic field effects.

From the above literature, no investigation has been reported for the mixed convection MHD flow of a Casson nanofluid over a nonlinear permeable stretching sheet with viscous dissipation. The basic governing equations are converted into ordinary differential equations by applying suitable similarity transformations and those equations were solved numerically by using an implicit finite difference method called as the Keller box method.

The aim of the present study is to investigate nanoparticle analysis for the Casson fluid model and the effect of Casson parameter on velocity, temperature and concentration fields illustrated with the help of graphical representations. 


\section{Flow Analysis}

Let us consider the two dimensional steady incompressible flow of a Casson nanofluid induced by a nonlinearly stretching sheet which is placed at $y=0$. The flow is confined to $y>0$. By keeping the origin is fixed and sheet is stretched with nonlinear velocity $u_{w}=a x^{n}$, where $n$ is nonlinear stretching parameter and $>0, x$ is the coordinate measured along the stretching surface. The nanofluid flows at $y=0$, where $y$ is the coordinate normal to the surface. The fluid is electrically conducted due to an applied magnetic field $B(x)$ normal to the stretching sheet. The magnetic Reynolds number is assumed small and so the induced magnetic field can be considered to be negligible. The wall temperature $T_{w}$ and the nanoparticle fraction $C_{w}$ are assumed constant at the stretching surface. When $y$ tends to infinity, the ambient values of temperature and nanoparticle fraction are denoted by $T_{\infty}$ and $C_{\infty}$, respectively. It is important to note that the constant temperature and the nanoparticle fraction of the stretching surface $T_{w}$ and $C_{w}$ are assumed to be greater than the ambient temperature and nanoparticle fraction $T_{\infty}, C_{\infty}$ respectively.

We also assume that the rheological equation of extra stress tensor $(\tau)$ for an isotropic and incompressible flow of a Casson fluid can be written as

$$
\tau= \begin{cases}2\left(\mu_{B}+\frac{p_{y}}{\sqrt{2 \pi}}\right) e_{i j}, & \pi>\pi_{c} \\ 2\left(\mu_{B}+\frac{p_{y}}{\sqrt{2 \pi_{c}}}\right) e_{i j}, & \pi<\pi_{c}\end{cases}
$$

where $\mu$ is the dynamic viscosity and $\mu_{B}$ is the plastic dynamic viscosity of the non-Newtonian fluid, $p_{y}$ is the yield stress of fluid, $\pi$ is the product of the component of deformation rate of $(i, j)$ th component and $\pi=e_{i j} e_{i j}, \pi_{c}$ is the critical value of $\pi$ based on non-Newtonian model.

In steady two dimensional flow the velocity field is given by $\mathbb{V}=[u(x, y), v(x, y), 0]$, the temperature distribution $T=T(x, y)$ and the nanoparticle volume fraction $C=C(x, y)$. Under the above considerations the equations governing the mixed convection MHD flow of Casson nanofluid past a nonlinearly stretching sheet with viscous dissipation are:

$$
\begin{gathered}
\frac{\partial u}{\partial x}+\frac{\partial v}{\partial y}=0 \\
u \frac{\partial u}{\partial x}+v \frac{\partial u}{\partial y}=v\left(1+\frac{1}{\beta}\right) \frac{\partial^{2} u}{\partial y^{2}}-\frac{\sigma B^{2}(x)}{\rho_{f}} u+g\left[\beta_{T}\left(T-T_{\infty}\right)+\beta_{C}\left(C-C_{\infty}\right)\right] \\
u \frac{\partial T}{\partial x}+v \frac{\partial T}{\partial y}=\alpha \frac{\partial^{2} T}{\partial y^{2}}+\tau\left\{D_{B} \frac{\partial C}{\partial y} \frac{\partial T}{\partial y}+\frac{D_{T}}{T_{\infty}}\left(\frac{\partial T}{\partial y}\right)^{2}\right\}+\frac{v}{C_{p}}\left(1+\frac{1}{\beta}\right)\left(\frac{\partial u}{\partial y}\right)^{2} \\
u \frac{\partial C}{\partial x}+v \frac{\partial C}{\partial y}=D_{B} \frac{\partial^{2} C}{\partial y^{2}}+\left(\frac{D_{T}}{T_{\infty}}\right) \frac{\partial^{2} T}{\partial y^{2}} .
\end{gathered}
$$

The boundary conditions for the above flow are

$$
\begin{aligned}
& y=0: u_{w}=a x^{n}, v=v_{w}, T=T_{w}, C=C_{w} \\
& y=\infty: u=0, v=0, T=T_{\infty}, C=C_{\infty} .
\end{aligned}
$$

Here $u$ and $v$ are the velocity components in the $x$-and $y$-direction respectively, $\alpha=\frac{k}{(\rho C)_{f}}$ is thermal diffusivity, $\sigma$ is electrical conductivity, $v$ is the kinematic viscosity, $\beta$ is the Casson fluid parameter, $\rho_{f}$ is the density of the base fluid, $g$ is the acceleration due to gravity, $\beta_{T}$ is the coefficient of thermal expansion, $\beta_{C}$ is the coefficient of expansion with concentration, $D_{B}$ is the Brownian diffusion coefficient and $D_{T}$ is the thermophoresis diffusion coefficient, $\tau=\frac{(\rho C)_{p}}{(\rho C)_{f}}$ is the ratio of nanoparticle heat capacity and the base fluid heat capacity, $c$ is the volumetric volume coefficient, $\rho_{p}$ is the density of the particles, and $C$ is rescaled na- 
noparticle volume fraction. We assume that the variable magnetic field $B(x)$ is of the form $B(x)=B_{0} x^{(n-1) / 2}$. Rana and Bhargava [15] introduced the following transformations.

$$
\begin{aligned}
& \eta=y \sqrt{\frac{a(n+1)}{2 v}} x^{\frac{(n-1)}{2}}, u=a x^{n} f^{\prime}(\eta), v=-\sqrt{\frac{a v(n+1)}{2}} x^{\frac{(n-1)}{2}}\left[f(\eta)+\frac{n-1}{n+1} \eta f(\eta)\right] \\
& \theta(\eta)=\frac{T-T_{\infty}}{T_{w}-T_{\infty}}, \quad \phi=\frac{C-C_{\infty}}{C_{w}-C_{\infty}}
\end{aligned}
$$

And assume $v_{w}=-\sqrt{\frac{a v(n+1)}{2}} x^{\frac{(n-1)}{2}} S$, where $S$ is the suction parameter.

By substituting the above transformations (6) in Equations (2)-(4) the governing equations are reduced to

$$
\begin{gathered}
\left(1+\frac{1}{\beta}\right) f^{\prime \prime \prime}+f f^{\prime \prime}-\frac{2}{n+1}\left(n f^{\prime 2}-G r \theta-G c \phi\right)-M f^{\prime}=0 . \\
\frac{1}{P r} \theta^{\prime \prime}+f \theta^{\prime}+N b \phi^{\prime} \theta^{\prime}+N t \theta^{\prime 2}+\left(1+\frac{1}{\beta}\right) E c f^{\prime 2}=0 . \\
\phi^{\prime \prime}+L e f \phi^{\prime}+\frac{N t}{N b} \theta^{\prime \prime}=0 .
\end{gathered}
$$

Then the transformed boundary conditions are

$$
\begin{gathered}
f(0)=S, f^{\prime}(0)=1, \theta(0)=1, \phi(0)=1, \\
f^{\prime}(\infty)=0, \theta(\infty)=0, \phi(\infty)=0,
\end{gathered}
$$

where prime denotes differentiation with respect to $\eta$. The physical parameters involved in the above equations are defined as $\operatorname{Pr}=\frac{v}{\alpha}$ is Prandtl number, $L e=\frac{v}{D_{B}}$ is Lewis number, $N b=\frac{D_{B\left(C_{w}-C_{\infty}\right)(\rho C)_{p}}}{v(\rho C)_{f}}$ is the Brownian motion parameter, $N t=\frac{D_{T\left(T_{w}-T_{\infty}\right)(\rho C)_{p}}}{T_{\infty} v(\rho C)_{f}}$ is the thermophoresis parameter, $M=\frac{2 \sigma B_{0}^{2}}{a \rho_{f}(n+1)}$ is magnetic parameter, $E c=\frac{u_{w}^{2}}{C_{p}\left(T_{w}-T_{\infty}\right)}$ Eckert number, $G r=\frac{g \beta_{T}\left(T_{w}-T_{\infty}\right)}{a^{2} x^{2 n-1}}$ is the local Grashof number and $G c=\frac{g \beta_{C}\left(C_{w}-C_{\infty}\right)}{a^{2} x^{2 n-1}}$ is the local modified Grashof number.

The quantities of the skin friction coefficient $C_{f}$, the local Nusselt number $N u_{x}$ and local Sherwood number $S h_{x}$ given as below:

$$
C_{f}=\frac{\tau_{w}}{\rho u_{w}^{2}}, \text { where } \tau_{w}=\mu_{B}\left(1+\frac{1}{\beta}\right)\left(\frac{\partial u}{\partial y}\right)_{y=0}, N u_{x}=\frac{x q_{w}}{k\left(T_{w}-T_{\infty}\right)}, S h_{x}=\frac{x q_{m}}{D_{B}\left(C_{w}-C_{\infty}\right)},
$$

where $k$ is the thermal conductivity of the nanofluid and $q_{w}, q_{m}$ are the heat and mass fluxes at the surface respectively given by

$$
q_{w}=-k\left(\frac{\partial T}{\partial y}\right)_{y=0}, q_{m}=-D_{B}\left(\frac{\partial C}{\partial y}\right)_{y=0} .
$$

By substituting Equation (6) into Equations (12)-(13), we will get

$$
\operatorname{Re}_{x}^{1 / 2} C_{f}=\left(1+\frac{1}{\beta}\right) f^{\prime \prime}(0), \quad R e_{x}^{-1 / 2} N u_{x}=-\sqrt{\frac{n+1}{2}} \theta^{\prime}(0), R e_{x}^{-\frac{1}{2}} S h_{x}=-\sqrt{\frac{n+1}{2}} \phi^{\prime}(0)
$$

where $R e_{x}=\frac{u_{w} X}{v}$ which is the local Reynolds number. 


\section{Numerical Solution}

As the ordinary differential Equations (7)-(9) are non-linear, we cannot get the closed form solution. Hence the equations subject to the boundary conditions (10)-(11) are solved numerically using Keller-Box method, as mentioned by Cebeci and Bradshaw [28]. According to Vajravelu et al. [29], the main steps involved in this method to get the numerical solutions are given below.

1) The Ordinary Differential Equations are converted into a system of first order equations.

2) Write the finite differences for the first order equations.

3) Linearize the algebraic equations by using Newton's method and write them in vector form.

4) Solve the linearized difference equations by the block tridiagonal elimination technique.

To get the accuracy of this method the appropriate initial guesses have been chosen.

The following initial guesses are chosen.

$$
f_{0}(\eta)=1+S-\mathrm{e}^{-\eta}, \theta_{0}(\eta)=\mathrm{e}^{-\eta}, \phi_{0}(\eta)=\mathrm{e}^{-\eta} .
$$

\section{Results and Discussions}

The aim of the present study is to analyze the effects of various emerging parameters on velocity, temperature and concentration profiles over a nonlinearly stretching sheet. The similarity transformations were used to transform the governing partial differential equations to nonlinear coupled ordinary differential equations. Later, those equations were solved by using an implicit finite difference technique called as Keller-Box method.

The results obtained in the study are compared with the existing literature and found in good agreement which is presented in the Table 1.

Numerical values of skin friction, Nusselt number and Sherwood number are presented in the Table 2, Table 3 and Table 4 respectively.

Figure 1 explains the variations in the velocity with respect to the magnetic parameter $M$, when $M$ increases the velocity decreases this is because the transverse magnetic field creates the Lorentz forces. It is a resistive force similar to the drag force which will result in the deceleration of the flow.

The variations in velocity with respect to Casson fluid parameter $\beta$ presented in the Figure 2 it was found that increase in $\beta$ increases the fluid viscosity this causes the decreasing in fluid velocity. Increase in nonlinear stretching parameternmakes the velocity of the fluid flow to be decreased. This result is presented in the Figure 3.

Figure 4 illustrates the variations in velocity with respect to suction parameter $S$. Due to increase of suction parameter the amount of fluid particles were drawn into the wall hence the boundary layer decreases. Figure 5 and Figure 6 visualizes the effects on the velocity profile with respect to $G r$ (local Grashoff number), Gc (local modified Grashoff number) and it was found that the increase in the $\mathrm{Gr}$ increases the velocity whereas increase in $G c$ increases the velocity of the fluid.

Figure 7 indicates that the temperature profile for different values of yield stress/Casson fluid parameter. It can be seen that increasing the values of Casson fluid parameter reduces the temperature and thermal boundary layer thickness.

Figure 8 exhibits the influence of thermoporesis parameter $N t$ on temperature distribution.

\begin{tabular}{|c|c|c|c|c|c|c|c|c|}
\hline \multirow{2}{*}{$n$} & \multirow{2}{*}{$\operatorname{Pr}$} & \multirow{2}{*}{ Le } & \multicolumn{3}{|c|}{$-\theta^{\prime}(0)$} & \multicolumn{3}{|c|}{$-\phi^{\prime}(0)$} \\
\hline & & & Rana \& Bhargava [15] & Mabood [16] & Present study & Rana \& Bhargava [15] & Mabood [16] & Present study \\
\hline 0.2 & 0.7 & 2 & 0.3299 & 0.3295 & 0.3296 & 0.8132 & 0.8134 & 0.8135 \\
\hline 0.3 & 0.7 & 2 & 0.3216 & 0.3262 & 0.3262 & 0.7965 & 0.8067 & 0.8068 \\
\hline 3.0 & 0.7 & 2 & 0.3053 & 0.3050 & 0.3050 & 0.7630 & 0.7633 & 0.7633 \\
\hline 10.0 & 0.7 & 2 & 0.3002 & 0.2999 & 0.2999 & 0.7524 & 0.7527 & 0.7527 \\
\hline 20.0 & 0.7 & 2 & 0.2825 & 0.2986 & 0.2986 & 1.4548 & 0.7500 & 0.7500 \\
\hline
\end{tabular}


Table 2. Calculation of skin friction coefficient for various values of $S, G r, G c$ and $\beta$ when $N b=N t=E c=0.1$, $\operatorname{Pr}=6.2, L e=5$.

\begin{tabular}{|c|c|c|c|c|c|}
\hline$S$ & $\beta$ & $M$ & $G r$ & Gc & $-\left(1+\frac{1}{\beta}\right) f^{\prime \prime}(0)$ \\
\hline 1 & 1.5 & 2 & 1.0 & 1.0 & 2.5985 \\
\hline 2 & & & & & 3.3398 \\
\hline \multirow[t]{13}{*}{3} & & & & & 4.1214 \\
\hline & 0.5 & & & & 3.3621 \\
\hline & & & & & 2.8109 \\
\hline & & & & & 2.5985 \\
\hline & & 0 & & & 1.7169 \\
\hline & & 1 & & & 2.2066 \\
\hline & & 2 & & & 2.5985 \\
\hline & & & 0 & & 2.7092 \\
\hline & & & 2 & & 2.4880 \\
\hline & & & 4 & & 2.2675 \\
\hline & & & & 0 & 2.7534 \\
\hline & & & & 2 & 2.4445 \\
\hline & & & & 4 & 2.1391 \\
\hline
\end{tabular}

Table 3. Calculation of Nusselt number for various values of $\beta, P r, N b, N t, E c$ when $M=n=2, S=1, G r=G c=1.0$, $L e=5$.

\begin{tabular}{cccccc}
\hline$\beta$ & $P r$ & $N b$ & $N t$ & $E c$ & $-\theta^{\prime}(0)$ \\
\hline 0.5 & 6.2 & 0.1 & 0.1 & 0.1 & 3.7545 \\
1.0 & & & 3.8154 \\
1.5 & & & 3.8397 \\
1.5 & 0.8 & & 0.9110 \\
& 1.0 & & 1.0782 \\
& 5.0 & & 3.3351 \\
& 0.1 & & 3.8397 \\
& 0.3 & & 1.8233 \\
& 0.5 & & 0.7436 \\
& & 0.1 & 3.8397 \\
& & 0.3 & 2.8047 \\
& & 0.5 & 2.0878 \\
& & & 3.2976 \\
& & & 2.2132 \\
& & 0.2 & 1.1287 \\
\hline
\end{tabular}

The enhancement of thermophoretic effects causes the migration of nanoparticles from the hot surface to the cold ambient fluid as a consequence of this the temperature increases in the boundary layer.

From Figure 9 it is observed that the increase in the Brownion motion parameter $N b$ increases the temperature. 
Table 4. Calculation of Sherwood number for various values of $L e, N b, N t$ when $\beta=1.5, M=n=2, S=1$, $G r=G c=0.1, E c=0.1$.

\begin{tabular}{cccc}
\hline$L e$ & $N b$ & $N t$ & $-\phi^{\prime}(0)$ \\
\hline 5 & 0.2 & 0.2 & 3.8002 \\
7 & & & 6.1857 \\
9 & & & 8.4285 \\
& 0.1 & & 0.0127 \\
& 0.3 & & 4.8979 \\
& 0.5 & 0.1 & 5.5477 \\
& & 0.3 & 4.5172 \\
& & 0.5 & 3.3830 \\
\hline
\end{tabular}

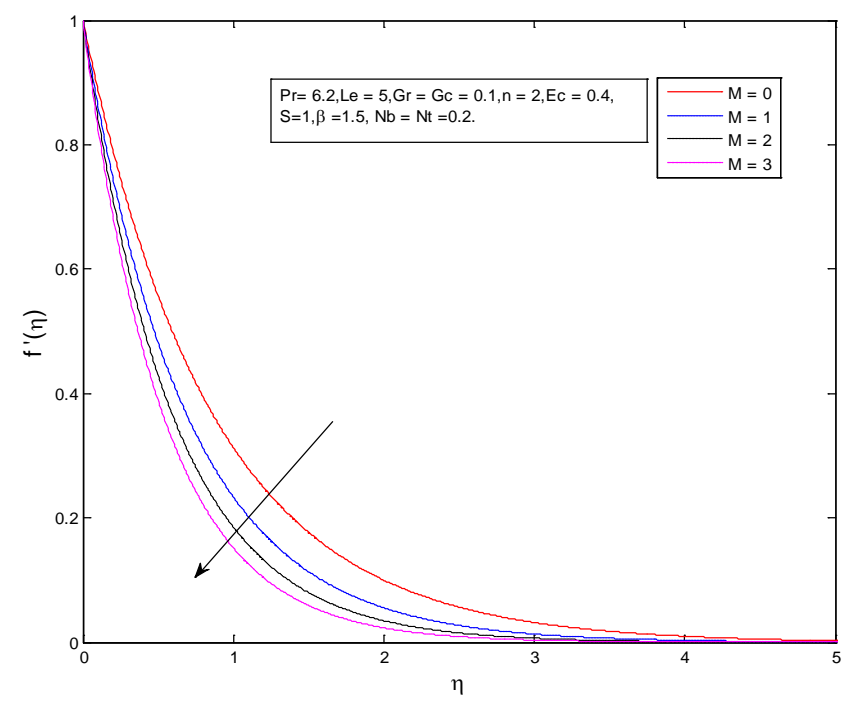

Figure 1. Velocity profiles for different values of magnetic parameter $M$.

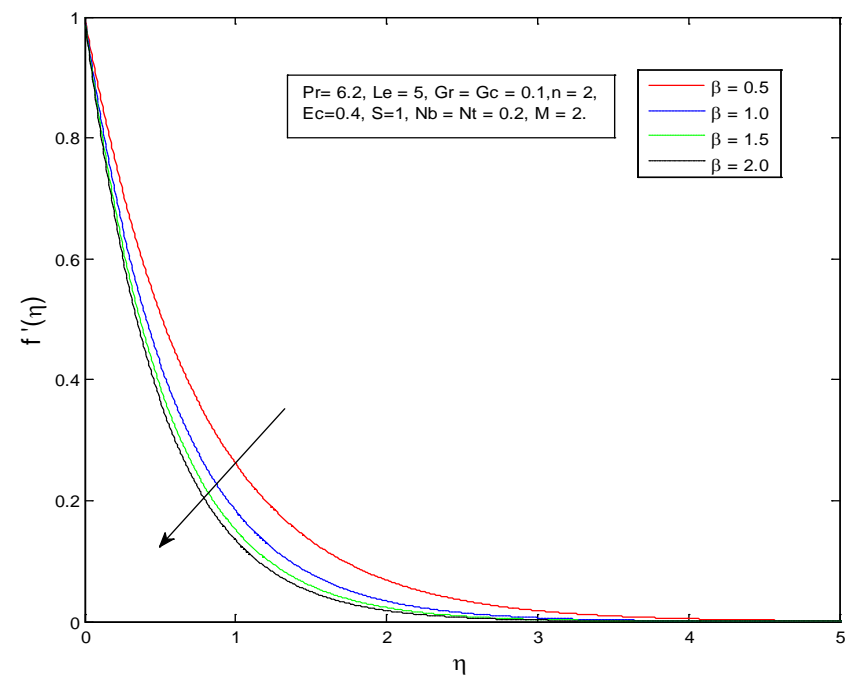

Figure 2. Velocity profiles for different values of Cason parameter $\beta$. 


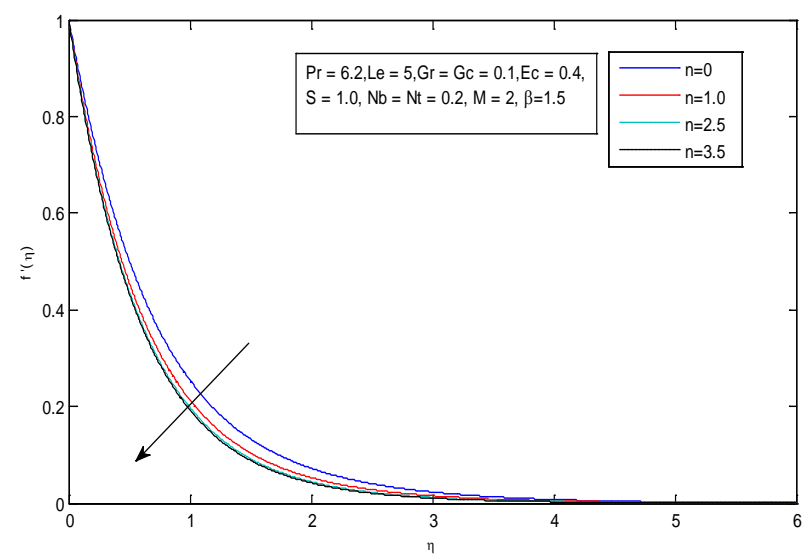

Figure 3. Velocity profiles for different values of nonlinear stretching parameter $n$.

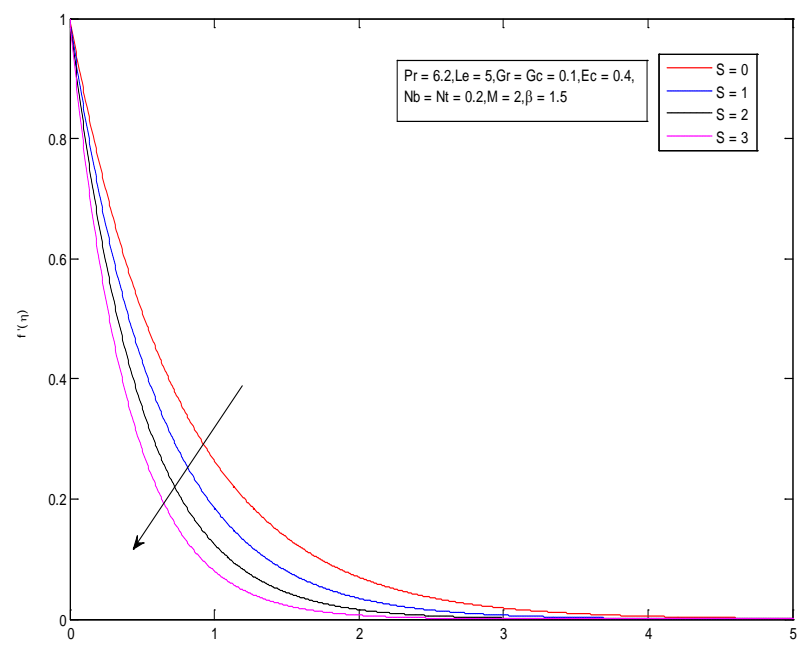

Figure 4. Velocity profiles for different values of suction parameter $S$.

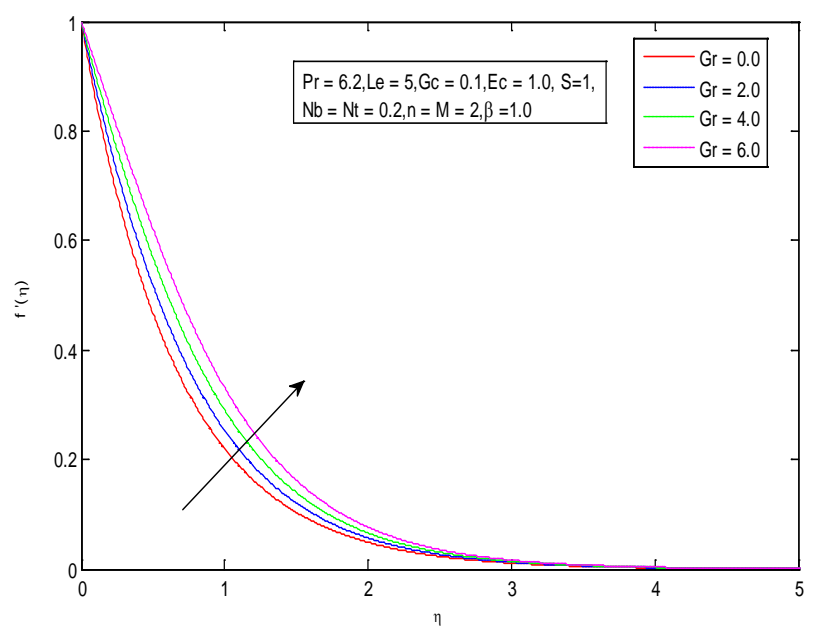

Figure 5. Velocity profiles for various values of local Grashoff number $\mathrm{Gr}$. 


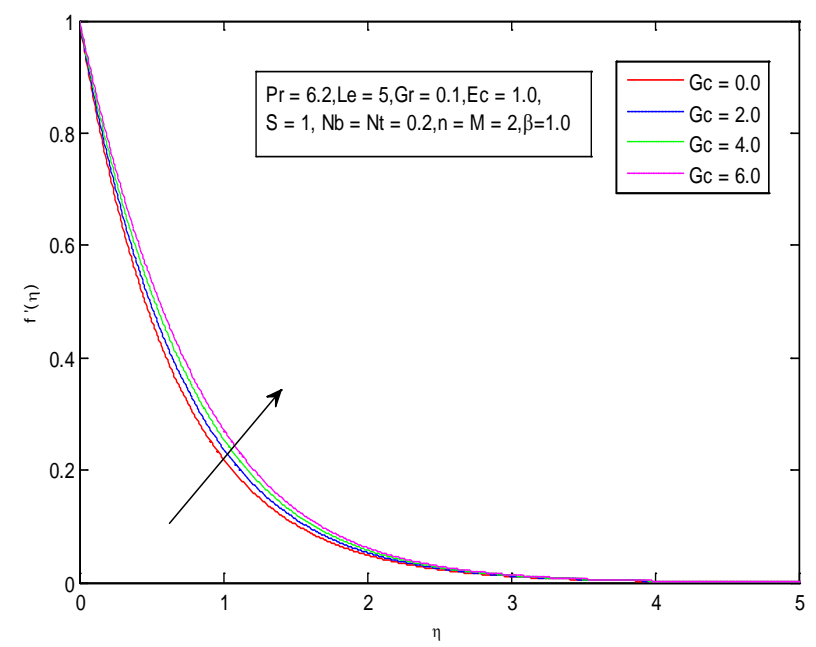

Figure 6. Velocity profiles for various values of local modified Grashoff number $G c$.

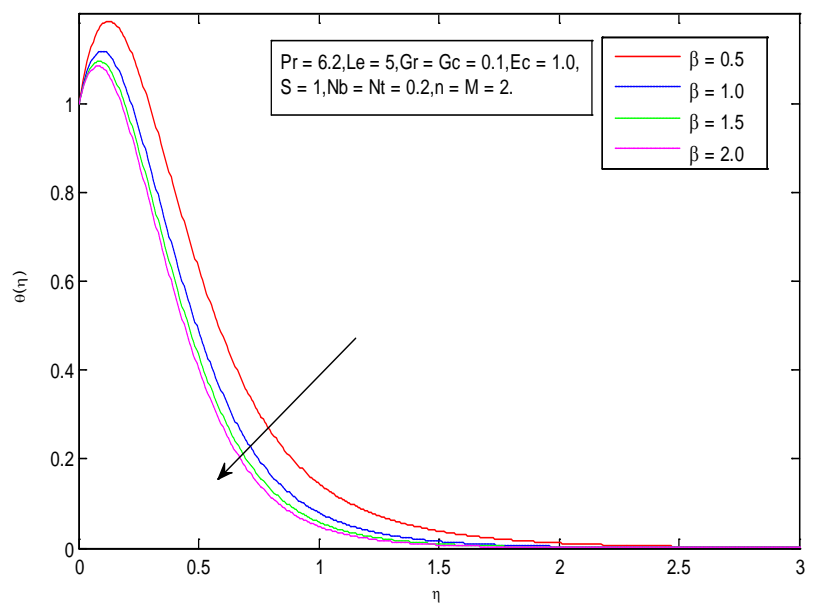

Figure 7. Temperature profiles for various values of Casson parameter $\beta$.

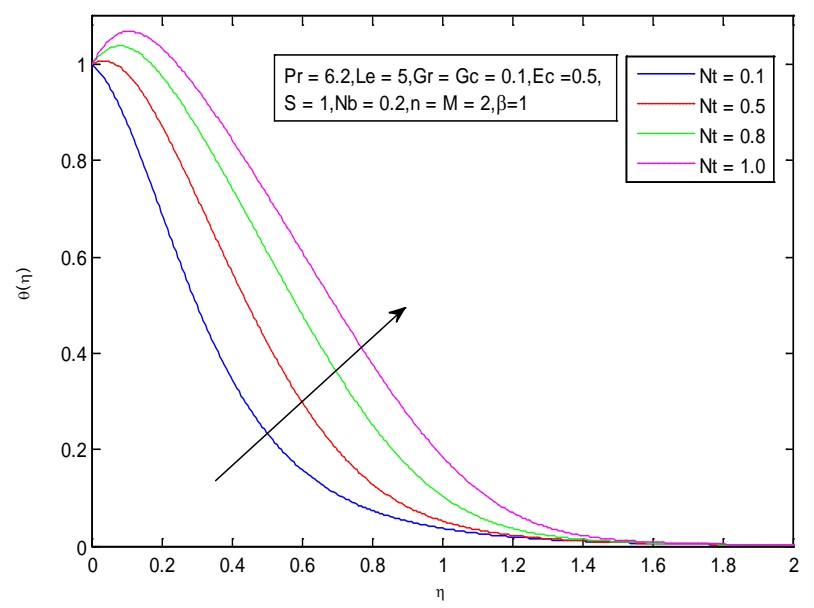

Figure 8. Temperature profiles for various values of thermoporesis parameter $N t$. 
From Figure 10 it is observed that the reversal flow happened this is because of the temperature enhancement occurs as heat energy is stored in the fluid due to frictional heating. Whereas from Figure 11 it is observed that temperature slightly decreases with increasing values of local Grashoff number $\mathrm{Gr}$.

Figure 12 and Figure 13 prepared to show the influence of thermoporesis parameter Nt and Brownian motion parameter $N b$ on nanoparticle concentration. From the figures it is clear that nanoparticle concentration increases with increasing values of thermoporetic parameter Nt. On the other hand Brownian motion serves to warm the boundary layer and simultaneously increases particle displacement away from the fluid regime, thereby accounting for the reduced concentration magnitudes. The larger values of Brownian motion parameter $\mathrm{Nb}$, it reduces the nanoparticle concentration.

Figure 14 presents the effect of Lewis number on dimensionless nanoparticle concentration. An increase in Lewis values will reduce the profile of nanoparticle concentration, and larger $L e$ values will also suppress concentration profile. From Figure 15 it is noticed that nanoparticle concentration is a decreasing function of local modified Grashoff number.

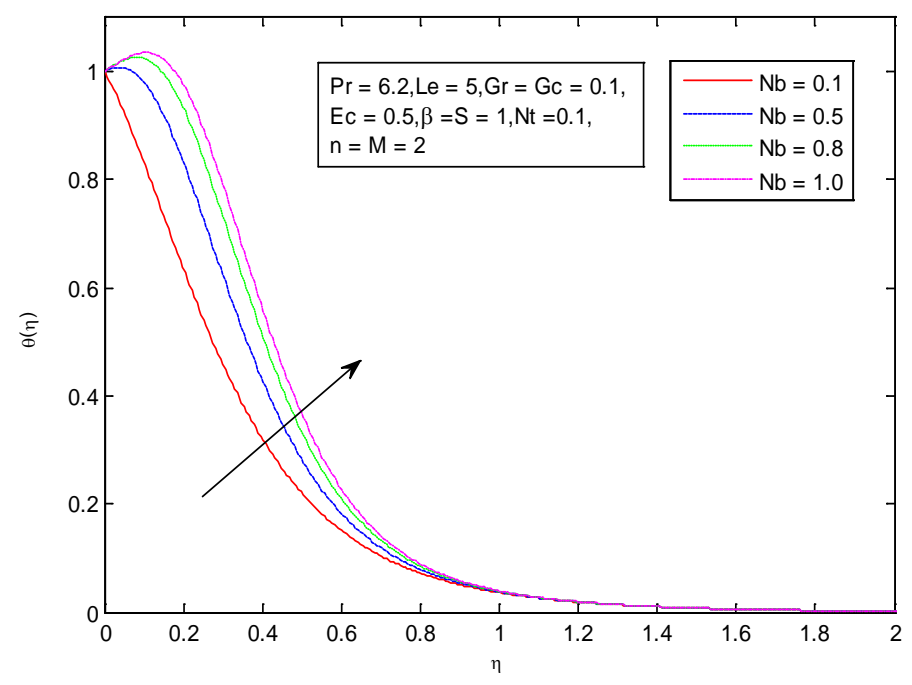

Figure 9. Temperature profiles for various values of Brownian motion parameter $N b$.

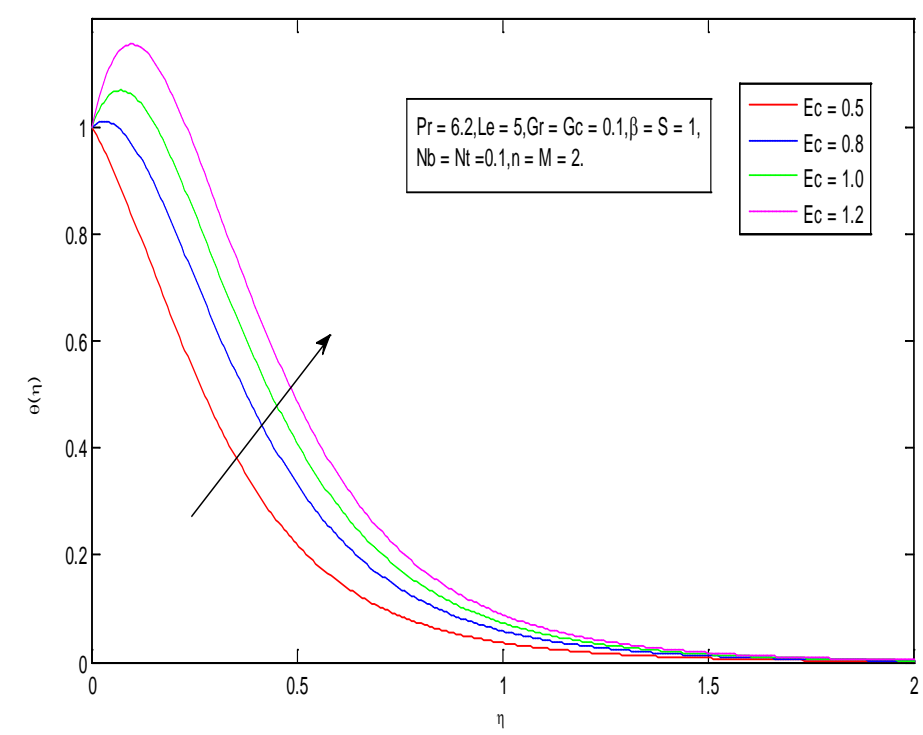

Figure 10. Temperature profiles for various values of Eckert number Ec. 


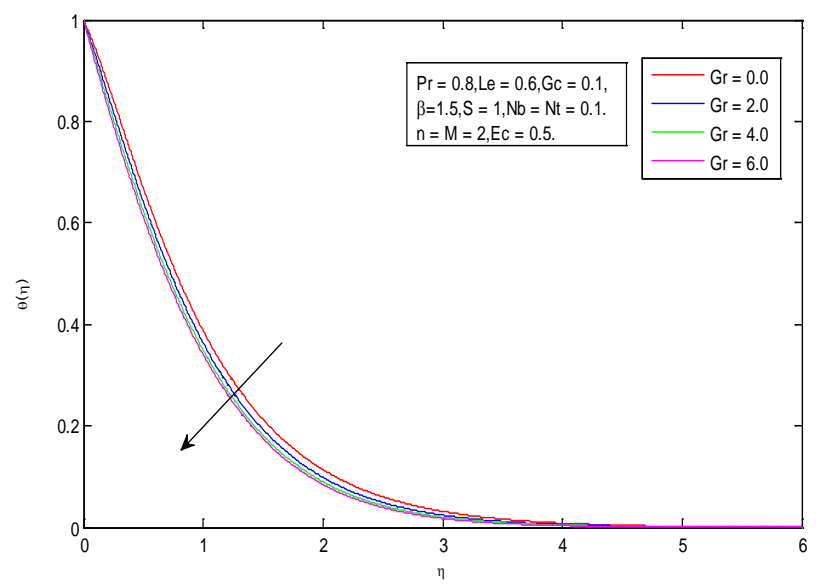

Figure 11. Temperature profiles for various values of local Grashoff number $G r$.

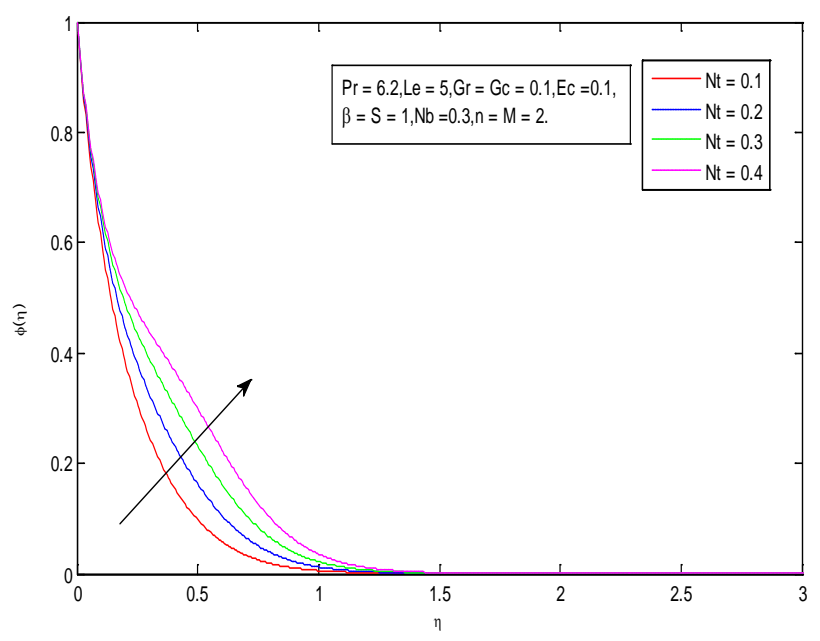

Figure 12. Concentration profiles for various values of thermoporesis parameter Nt.

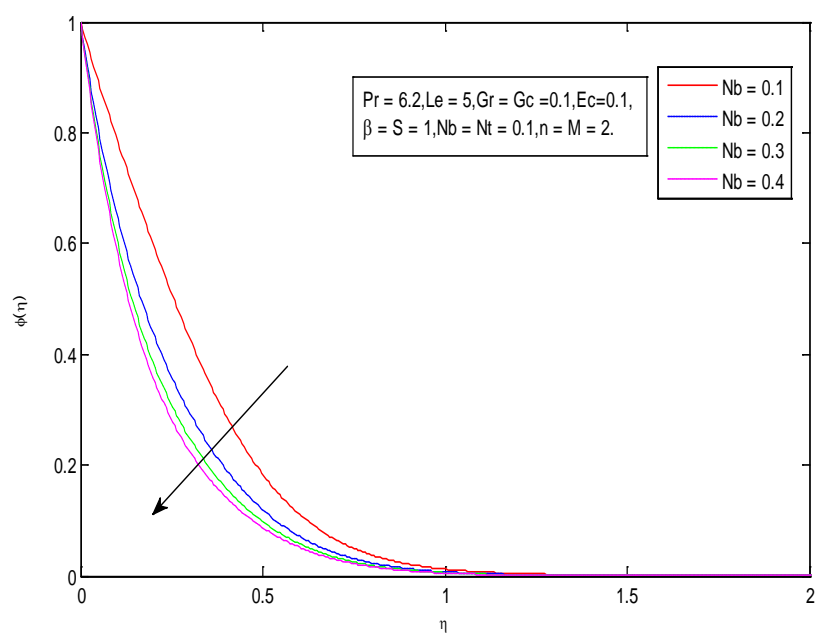

Figure 13. Concentration profiles for various values of Brownian motion parameter $\mathrm{Nb}$. 


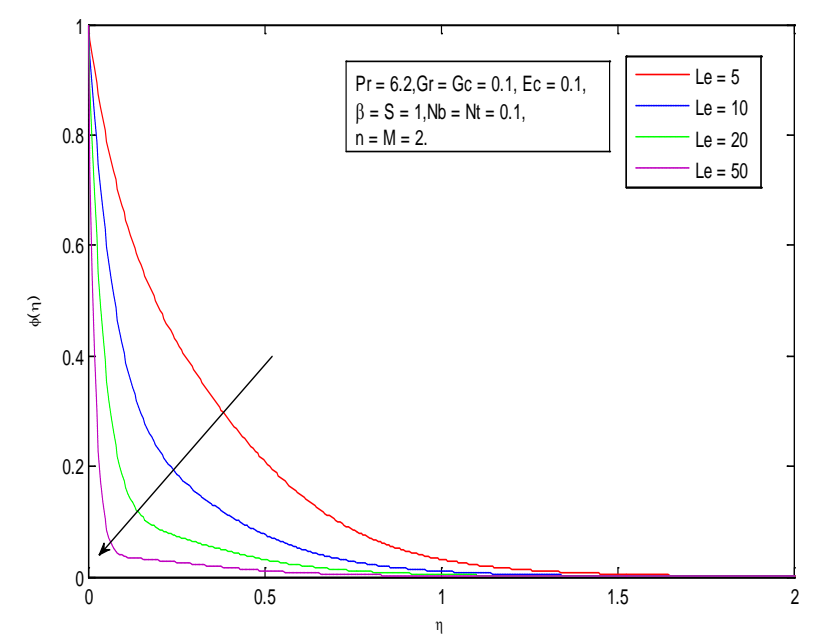

Figure 14. Concentration profiles for various values of Lewis number $L e$.

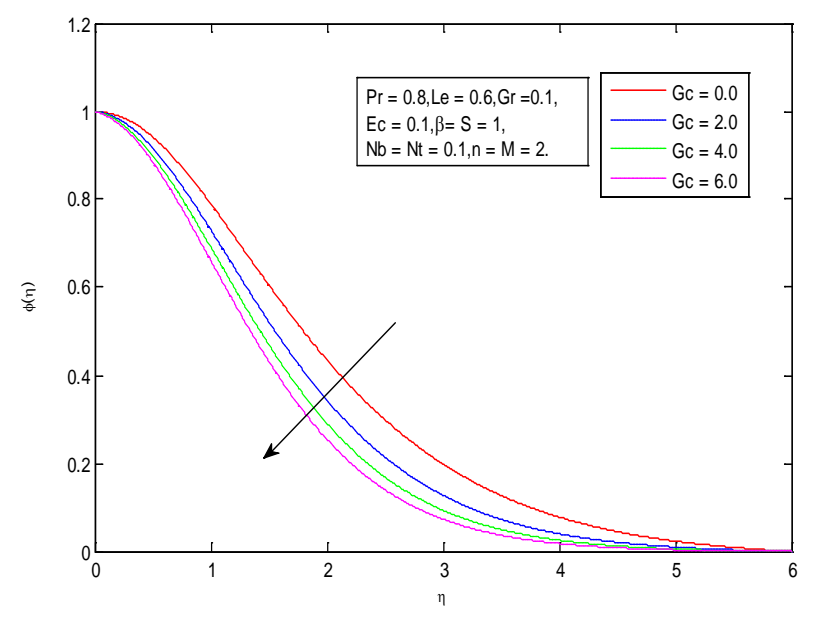

Figure 15. Concentration profiles for various values of local modified Grashoff number Gc.

\section{Conclusions}

A numerical study was investigated for the mixed convection MHD flow of a Casson nanofluid over a nonlinear permeable stretching sheet with viscous dissipation with the help of an implicit finite difference method known as Keller-Box method. A parametric study is performed to explore the effects of various governing parameters on the fluid flow and heat transfer characteristic. Following conclusions give the brief results of the present study.

1) Increase in the values of magnetic parameter decreases the velocity profile.

2) Increase in nonlinear stretching parameter $n$ decreases the velocity profile.

3) It is found that larger values of Casson parameter lead to decrease the velocity and temperature.

4) Temperature is enhanced for the higher values of Eckert number.

5) Increase in the local Grashoff number reduces the temperature.

6) Nanoparticle concentration is decreased for the larger values of local modified Grashoff number.

7) Nanoparticle concentration is enhanced for the higher values of Lewis number.

\section{Acknowledgements}

This research was supported by University Grants Commission-India under Faculty Development Programme 
The author gratefully acknowledges the support of UGC.

\section{References}

[1] Sakiadis, B.C. (1961) Boundary-Layer Behavior on Continuous Solid Surfaces. AIChE Journal, 7, 26-28. http://dx.doi.org/10.1002/aic.690070108

[2] Sakiadis, B.C. (1961) Boundary Layer Behavior on Continuous Solid Surfaces: II. Boundary Layer on a Continuous Flat Surface. AIChE Journal, 7, 221-225. http://dx.doi.org/10.1002/aic.690070211

[3] Erickson, L.E., Fan, L.T. and Fox, V.G. (1966) Heat and Mass Transfer on Moving Continuous Flat Plate with Suction or Injection. Industrial and Engineering Chemistry Fundamentals, 5, 19-25. http://dx.doi.org/10.1021/i160017a004

[4] Magyari, E. and Keller, B. (2000) Exact Solutions for Self Similar Boundary Layer Flows Induced by Permeable Stretching Walls. European Journal of Mechanics B-Fluids, 19, 109-122. http://dx.doi.org/10.1016/S0997-7546(00)00104-7

[5] Gupta, P.S. and Gupta, A.S. (1977) Heat and Mass Transfer on a Stretching Sheet with Suction or Blowing. Canadian Journal of Chemical Engineering, 55, 744-746. http://dx.doi.org/10.1002/cjce.5450550619

[6] Vajravelu, K. (2001) Viscous Flow over a Nonlinearly Stretching Sheet. Applied Mathematics and Computation, 124, 281-288. http://dx.doi.org/10.1016/S0096-3003(00)00062-X

[7] Bhargava, R., Sharma, S., Takhar, H.S., Beg, O.A. and Bhargava, P. (2007) Numerical Solutions for Micropolartransport Phenomena over a Nonlinear Stretching Sheet. Nonlinear Analysis Modeling and Control, 12, 45-63.

[8] Prasad, K.V., Vajravelu, K. and Datti, P.S. (2010) Mixed Convection Heat Transfer over a Non-Linear Stretching Surface with Variable Fluid Properties. International Journal of Non-Linear Mechanics, 45, 320-330. http://dx.doi.org/10.1016/j.ijnonlinmec.2009.12.003

[9] Choi, S.U.S. (1995) Enhancing Thermal Conductivity of Fluids with Nanoparticles. Proceedings of the ASME International Mechanical Engineering Congress and Exposition, 66, 99-105.

[10] Khan, W.A. and Pop, I. (2010) Boundary-Layer Flow of a Nanofluid past a Stretching Sheet. International Journal of Heat and Mass Transfer, 53, 2477-2483. http://dx.doi.org/10.1016/j.jjheatmasstransfer.2010.01.032

[11] Buongiorno, J. (2006) Convective Transport in Nanofluids. Journal of Heat Transfer, 128, 240-250. http://dx.doi.org/10.1115/1.2150834

[12] VanGorder, R.A., Sweet, E. and Vajravelu, K. (2010) Nano Boundary Layers over Stretching Surfaces. Communications in Nonlinear Science and Numerical Simulation, 15, 1494-1500. http://dx.doi.org/10.1016/j.cnsns.2009.06.004

[13] Hassani, M., Tabar, M.M., Nemati, H., Domairry, G. and Noori, F. (2011) An Analytical Solution for Boundary Layer Flow of a Nanofluid Past a Stretching Sheet. International Journal of Thermal Science, 50, 2256-2263. http://dx.doi.org/10.1016/j.ijthermalsci.2011.05.015

[14] Akyildiz, F.T., Bellout, H., Vajravelu, K. and VanGorder, R.A. (2011) Existence Results for Third Order Nonlinear Boundary Value Problems Arising in Nano Boundary Layer Fluid Flows over Stretching Surfaces Nonlinear Analysis: Real World Applications, 12, 2919-2930. http://dx.doi.org/10.1016/j.nonrwa.2011.02.017

[15] Rana, P. and Bhargava, R. (2012) Flow and Heat Transfer of a Nanofluid over a Nonlinearlynstretching Sheet: A Numerical Study. Communications in Nonlinear Science and Numerical Simulation, 17, 212-226.

[16] Mabood, F., Khan, W.A. and Ismail, A.I.M. (2015) MHD Boundary Layer Flow and Heat Transfer of Nanofluids over a Nonlinear Stretching Sheet: A Numerical Study. Journal of Magnetism and Magnetic Materials, 374, 569-576. http://dx.doi.org/10.1016/j.jmmm.2014.09.013

[17] Fredrickson, A.G. (1964) Principles and Applications of Rheology. Prentice-Hall, Englewood Cliffs.

[18] Nakamura, M. and Sawada, T. (1988) Numerical Study on the Flow of a Non-Newtonian Fluid through an Axisymmetric Stenosis. ASME Journal of Biomechanical Engineering, 110, 137-143. http://dx.doi.org/10.1115/1.3108418

[19] Mustafa, M., Hayat, T., Pop, I. and Aziz, A. (2011) Unsteady Boundary Layer Flow of a Casson Fluid Due to an Impulsively Started Moving Flat Plate. Heat Transfer Asian Research, 40, 563-576.

[20] Nadeem, S., Haq, R.U. and Lee, C. (2012) MHD Flow of a Casson Fluid over an Exponentially Shrinking Sheet. Scientia Iranica, 19, 1550-1553. http://dx.doi.org/10.1016/j.scient.2012.10.021

[21] Bhattacharyya, K., Hayat, T. and Alsaedi, A. (2014) Exact Solution for Boundary Layer Flow of Casson Fluid over a Permeable Stretching/Shrinking Sheet. ZAMM, Zeitschrift für Angewandte Mathematik und Mechanik, 96, 522-528.

[22] Bhattacharyya, K., Hayatand, T. and Alsaedi, A. (2013) Analytic Solution for Magneto Hydrodynamic Boundary Layer Flow of Casson Fluid over a Stretching/Shrinking Sheet with Wall Mass Transfer. Chinese Physics B, 22, Article ID: 024702.

[23] Mukhopadhyay, S. (2013) Casson Fluid Flow and Heat Transfer over a Nonlinearly Stretching Surface. Chinese Phys- 
ics B, 22, Article ID: 074701.

[24] Kameswaran, P.K., Shaw, S. and Sibanda, P. (2014) Dual Solutions of Casson Fluid Flow over a Stretching or Shrinking Sheet. Sadhana, Indian Academy of Science, 39, 1573-1583.

[25] Haq, R.U., Nadeem, S., Khan, Z.H. and Okedayo, T.G. (2015) Convective Heat Transfer and MHD Effects on CassonNano Fluid Flow over a Shrinking Sheet. Central European Journal of Physics, 12, 862-871.

[26] Hussain, T., Shehzad, S.A., Alsaedi, A., Hayat, T. and Ramzan, M. (2015) Flow of Casson-Nano Fluid with Viscous Dissipation and Convective Conditions: A Mathematical Model. Journal of Central South University, 22, 1132-1140.

[27] Mustafa, M. and Khan, J.A. (2015) Model for Flow of Casson-Nano Fluid Past a Nonlinearly Stretching Sheet Considering Magnetic Field Effects. AIP Advances, 5, Article ID: 077148.

[28] Cebeci, T. and Bradshaw, P. (1984) Physical and Computational Aspects of Convective Heat Transfer. Springer, Berlin Heidelberg. http://dx.doi.org/10.1007/978-3-662-02411-9

[29] Vajravelu, K., Prasad, K.V. and Ng, C.-O. (2013) Unsteady Convective Boundary Layer Flow of a Viscous Fluid at a Vertical Surface with Variable Fluid Properties. Nonlinear Analysis: Real World Applications, 14, 455-464. http://dx.doi.org/10.1016/j.nonrwa.2012.07.008 